\title{
CARACTERIZAÇÃO AMBIENTAL NA BACIA DO CÓRREGO SARANDI ALUENTE DA LAGOA DA PAMPULHA EM BELO HORIZONTE - MG
}

Dayane de Jesus Pereira - Day_2408@yahoo.com.br

Centro Universitário de Belo Horizonte - UNIBH

Núbia Aparecida Ribeiro - nubiaribeiro1992@ gmail.com

Centro Universitário de Belo Horizonte - UNIBH

Elizabeth Rodrigues Brito Ibrahim - erbrito@bol.com.br

Centro Universitário de Belo Horizonte - UNIBH 


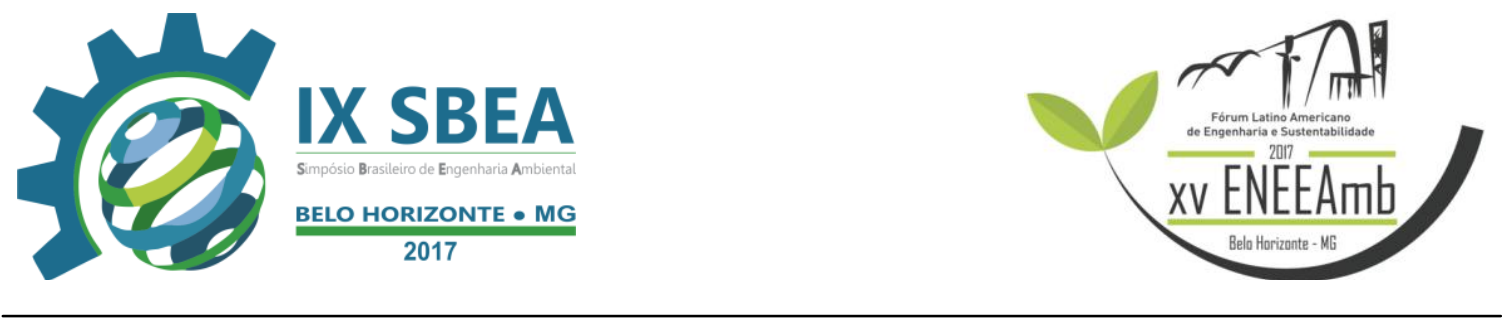

\section{RESUMO}

Os recursos hídricos é um tema muito importante devido a preocupação com sua crescente escassaz em função da alta demanda por este. O mau uso, ou o uso incorreto da água pode provocar poluição ao meio ambiente e a população que necessita desta fonte. Belo Horizonte possui vários cursos de água importantes bem como reservatórios que suprem a necessidade de abastecimento de toda população, dentre eles a lagoa da Pampulha se destaca, o que antes era fonte de abastecimento, hoje passa por um processo de recuperação, e vários estudos vem sendo realizados para que medidas adequadas sejam tomadas.

Palavras-chave: Recurso Hídrico, Poluição, Meio Ambiente, Caracterização Ambiental.

\section{INTRODUÇÃO/OBJETIVO}

Atualmente a água é alvo de muitos comentários, porém as ações voltadas para economia do recurso ainda são poucas, sendo que muitos sabem da sua importância para a existência da vida. Todas as espécies dependem da água como condição de sobrevivência. Segundo o Projeto Brasil das águas de 2012, a água é um dos únicos recursos naturais que se envolve em todos os aspectos da civilização humana, e ainda assim, sabendo da sua importância as pessoas e entidades continuam poluindo os rios e destruindo nascentes, gerando como impacto uma má qualidade ou até mesmo a sua escassez.

A água é utilizada em diversas e diferentes funções, e as principais são: abastecimento, geração de energia, irrigação, agricultura, navegação e para harmonia paisagística. Mesmo com todas as normas existente para o uso, ela tem sido cada vez mais, usada de maneira inadequada (MORAIS, ET. AL, 2002).

Segundo Alfredo Estevão de Barros Leite, 2004, a poluição das águas é hoje um dos principais problemas ambientais sofridos, não só no Brasil, como também no mundo inteiro, o que gera diversos efeitos negativos para saúde humana, fauna e flora, além disso esses problemas ocasionam também problemas para o abastecimento. 
Em Belo Horizonte existem diversos mananciais que podem contribuir para o abastecimento da população, todavia muitos deles encontram-se em más condições para o uso. Um dos exemplos da cidade é a lagoa da Pampulha, que na época de sua criação tinha como objetivo abastecer a região norte de Belo Horizonte e diminuir os efeitos causado pelas chuvas, permitindo o armazenamento dessa água proveniente da precipitação. Após sua criação o espaço foi transformado em centro de lazer e turismo, e assim começou a atrair não só os moradores que já frequentavam o local, como também turistas que gostavam de apreciar a bela paisagem. Entretanto o local que antes era preservado para o abastecimento, começou a ser alvo de poluição, e assim o sistema precisou ser interrompido (PROJETO MANUESÃO, 2016).

Por certo, existem alguns fatores de extrema importância para a agravação do problema, como é o caso do rio Sarandi, ele tem como destino final a lagoa, e junto com ele traz poluentes extremamente significativos e nocivos, afetando diretamente as questões socioambientais de toda população (RODRIGUES, 2015).

O córrego Sarandi está inserido na bacia do Ribeirão Onça, localizado no alto do Rios das Velhas, e encontra-se nas cidades de Belo Horizonte e Contagem, em Minas Gerais. A UTE-unidade territorial estratégica da bacia do Onça possui uma de 221,38 quilômetros quadrado atingindo cerca de 1,3 milhões de habitantes. O córrego nasce em Contagem, passa pela região norte de Belo Horizonte, encontra-se com o córrego Ressaca e desagua na lagoa da Pampulha. Durante seu percurso, o córrego recebe diferentes poluentes sem nenhum tipo de tratamento prévio, causando a poluição do mesmo, e acarretando diversos problemas, como: poluição da lagoa da Pampulha, Enchentes, Poluição visual, mal cheiro entre outros (PHCRV, 2015).

\section{METODOLOGIA}

A área de estudo do presente trabalho é o Córrego Sarandi cuja bacia hidrográfica está localizada entre os municípios de Contagem e Belo Horizonte, como mostra a figura 1.

Foi delimitada uma área no percurso do córrego para a aplicação da pesquisa como mostra a figura 2. 


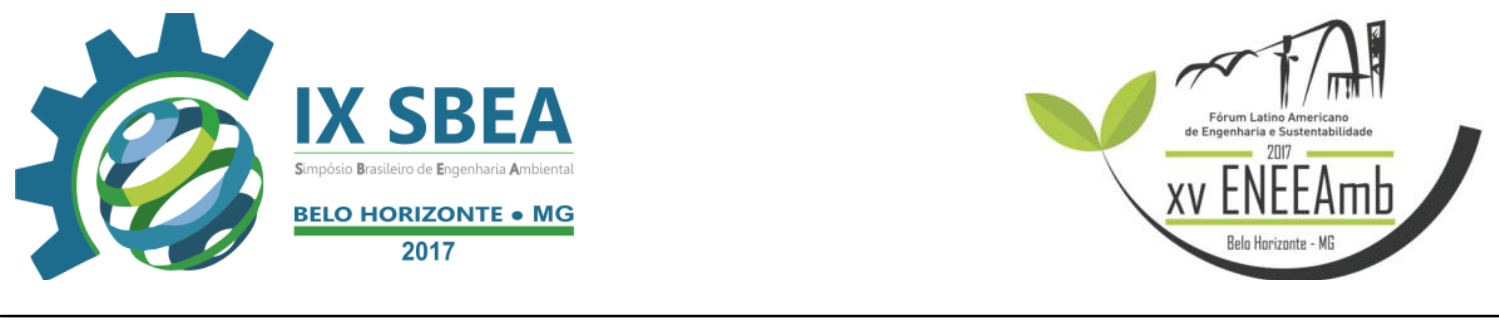

Buscou-se como base conceitual, a caracterização ambiental do córrego, de maneira a entender os pontos positivos e negativos na percepção dos moradores do seu entorno, bem como buscar a fundo sua situação atual real. Além disso uma busca através de dados do IBGE- Instituto Brasileiro de Geografia e Estatística, foi realizada para entender o perfil dessa população. Foi delimitado uma área para a realização da pesquisa como mostra a figura 2 , e foram analisada as seguintes perguntas:

1. Você acha o Rio importante para a comunidade?

2. Você já presenciou descarte inadequado de resíduos no Rio?

3. Você acha que a poluição do Rio é advinda prioritariamente dos moradores?

4. Existe coleta de lixo frequente na região?

5. O que a presença do Rio e seus aspectos traz para região?

6. Como a população pode colaborar para que o rio seja preservado?

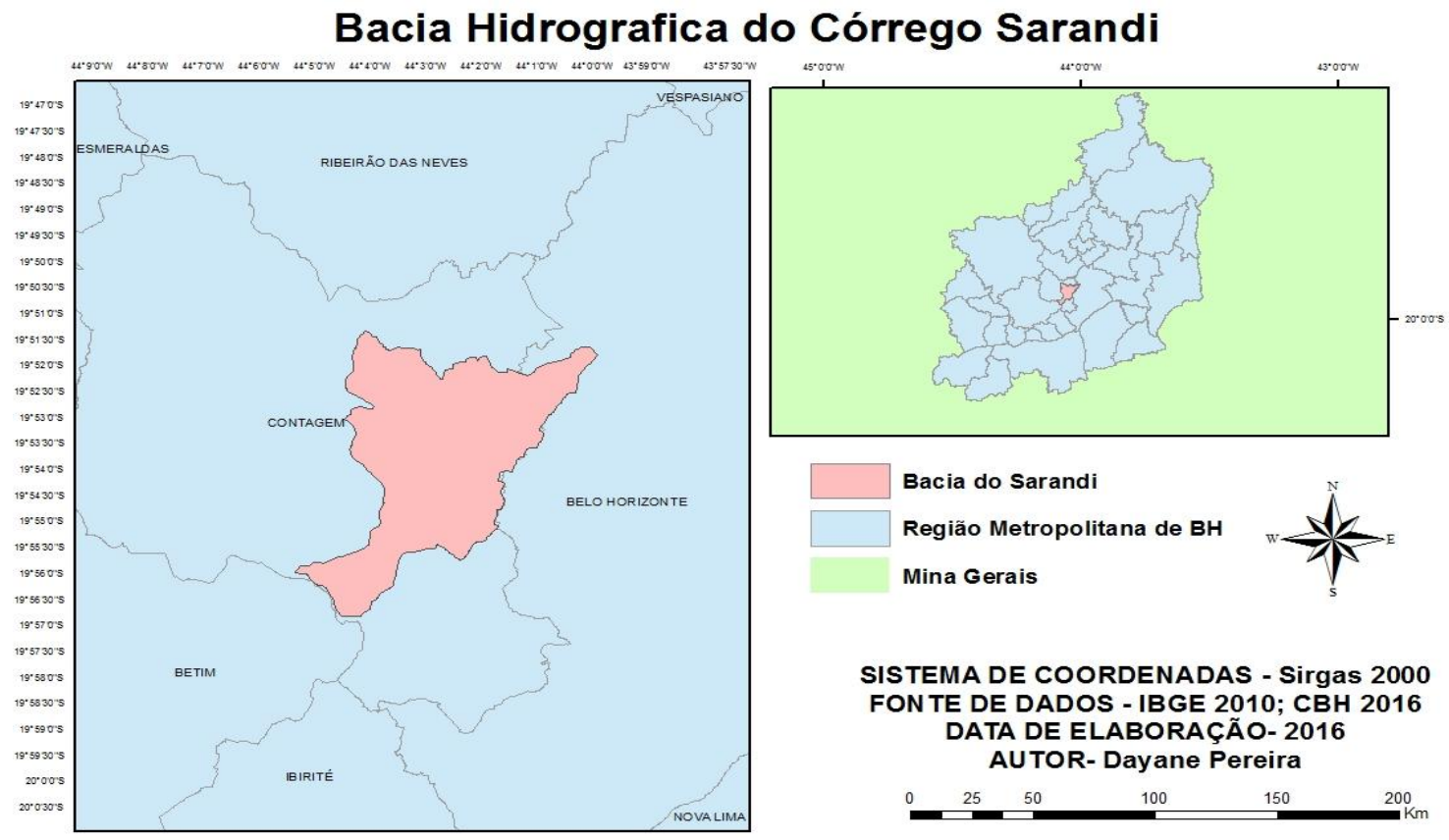

Figura 1 - Mapa de localização da bacia do Córrego Sarandi- MG Fonte - Elaborado pelos autores, 2016 

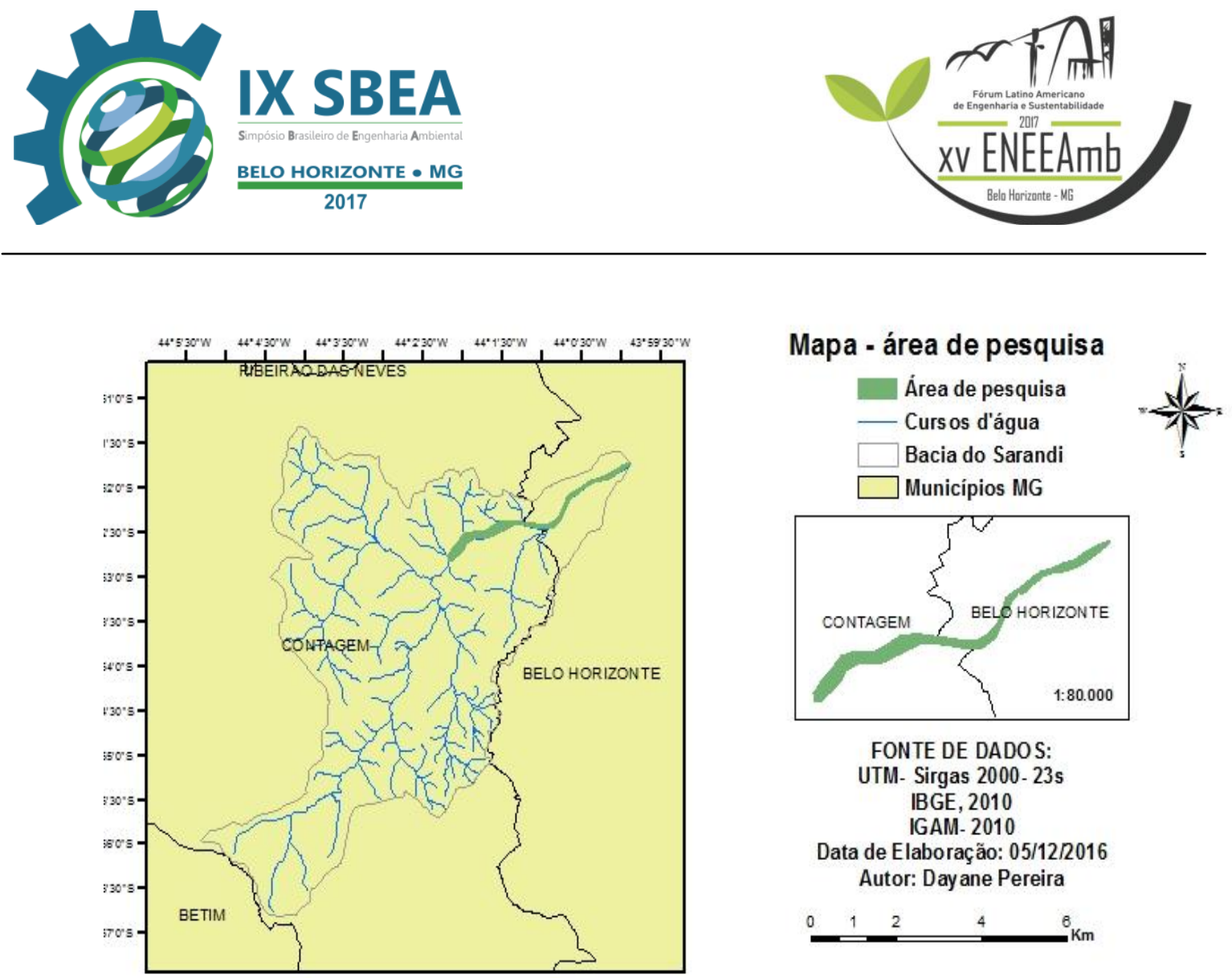

Figura 2 - Área da pesquisa no entorno do Córrego Sarandi- MG

Fonte - Elaborado pelos autores, 2016

\section{RESULTADOS E DISCUSSÃO}

\subsection{Bacia hidrográfica da Pampulha}

A lagoa da Pampulha foi inaugurada em 1993 pelo prefeito da cidade daquela época, e tinha como principal função amortecer os efeitos das chuvas e abastecer a região norte de Belo Horizonte, a lagoa faz parte do projeto arquitetônico projetada por Oscar Niemeyer, e se tornou referência para arquitetura moderna Brasileira (BATISTA, SD).

Segundo dados da prefeitura municipal de Belo Horizonte (PBH), quando a lagoa foi inaugurada, ela tinha capacidade de acumular cerca de 18 milhões de metros cúbicos, e em 1954 teve sua capacidade reduzida devido ao rompimento de seu vertedouro, permitindo a armazenagem de 13 milhões de metros cúbicos.

Com o crescimento populacional no início dos anos 50, que aumentava desordenadamente no entorno da bacia, e no entorno dos córregos que desagua na lagoa, a bacia começou a sofrer pela degradação, proveniente de bota fora clandestino, esgoto doméstico e industrial, movimentação de terra causada pelos loteamentos residenciais, o 
que além da poluição da lagoa, começou a causar também o alagamento em períodos de chuvas em áreas mais baixas da região (BATISTA, SD).

A figura 3 mostra as subdivisões da bacia hidrográfica da Pampulha.

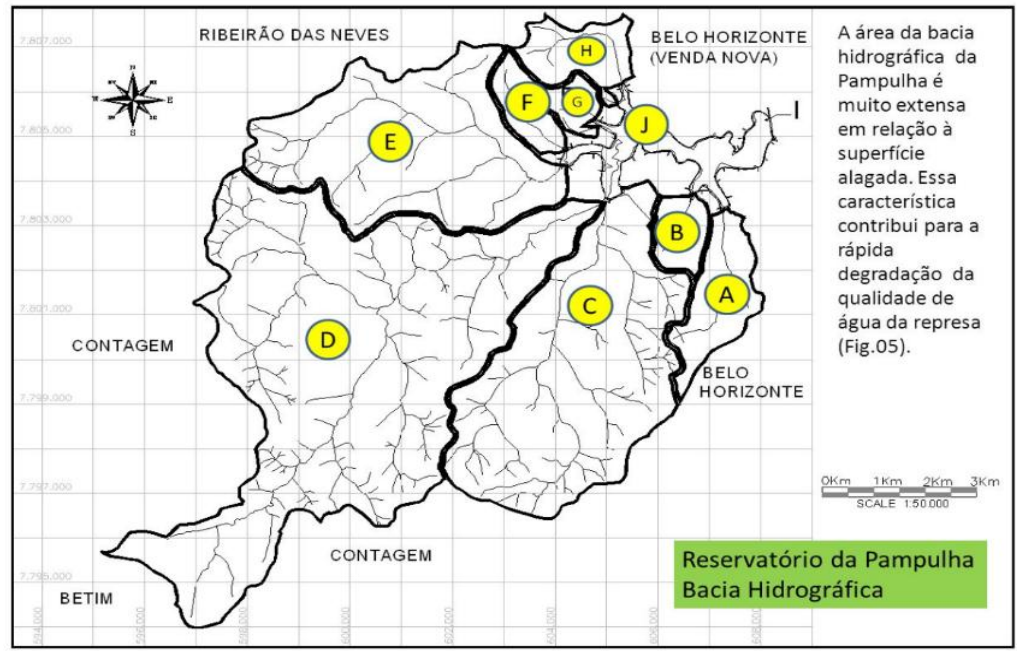

Legenda:

A Mergulhão

B) Tijuco

C) Ressaca

(D) Sarandi

E) Água suja

F) Braúnas

G Córrego AABB

(H) Micro bacia do Céu Azul

Figura 3- Bacia Hidrográfica da Pampulha

Fonte - SUDECAP, 2002

\subsection{Córrego Sarandi}

O córrego Sarandi nasce em Contagem e ao chegar em Belo Horizonte encontrase com o córrego Ressaca e segue até desaguar na lagoa da Pampulha, o córrego é mencionado como um dos principais poluidores da lagoa. Seus aspectos são provenientes da poluição causada no decorrer de seu percurso. Segundo dados da PBH, 2016 cerca de 4 toneladas de lixo são descarregadas na lagoa através do córrego Ressaca e Sarandi (PBH,2016).

Além da significativa contribuição para a poluição da lagoa da Pampulha, o córrego apresenta em época de alta precipitação, pontos de alagamento que acarreta em vários danos para a população que vive no seu entorno e para o meio ambiente. Embora o percurso do rio tenha passado por algumas obras para melhorar esses aspectos, 

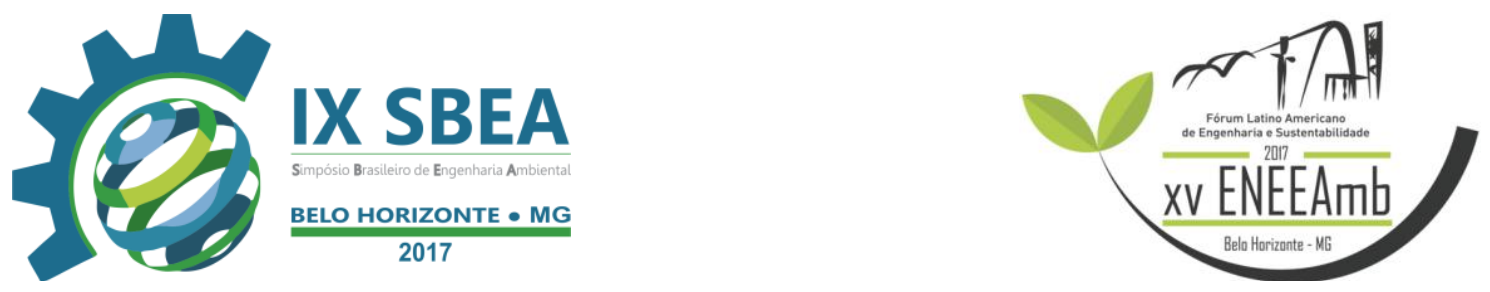

estudos realizados pelo Comitê de Bacias Hidrográficas de Belo Horizonte, aponta que após essas obras a área foi alagada novamente (CBHBH,2016).

O córrego Sarandi aponta diversos pontos negativos e ele juntamente com o córrego ressaca são responsáveis por cerca de $70 \%$ da poluição da lagoa da Pampulha. (COPASA,2016).

A pesquisa foi realizada em diferentes pontos do entorno do rio, essa área foi dividida em 3 partes como mostra a figura 4, todos as pessoas entrevistadas eram moradores da região, e ao todo 105 moradores foram ouvidos.

A pesquisa teve como principal objetivo compreender o que os moradores entendem sobre a presença do rio e qual conhecimento possuem sobre a preservação do mesmo.

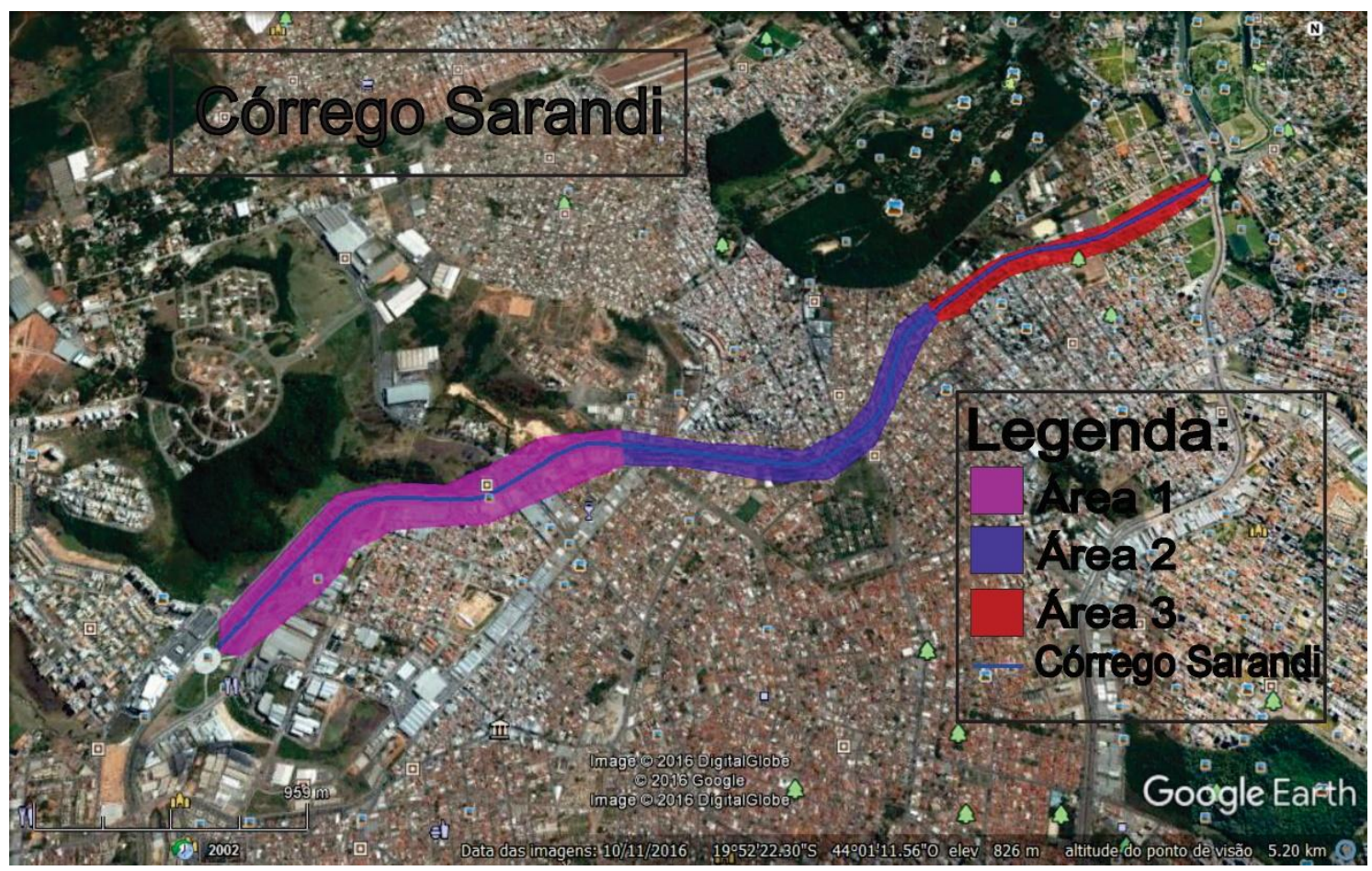

Figura 4- Áreas de pesquisa- Córrego Sarandi

Fonte - GOOGLE EARTH, 2016

\subsection{Perfil da população}

Através dos pontos de coleta da pesquisa, foi levantado o perfil demográfico da população de acordo com o senso do IBGE 2010, e assim analisou-se a média salarial (figura 5) e os tipos de moradias (figura 6) ocupados por essa população. 


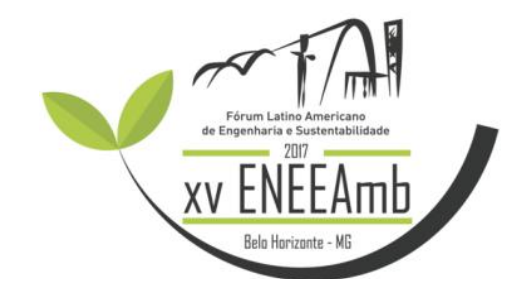

\section{Renda média por ponto de coletado}

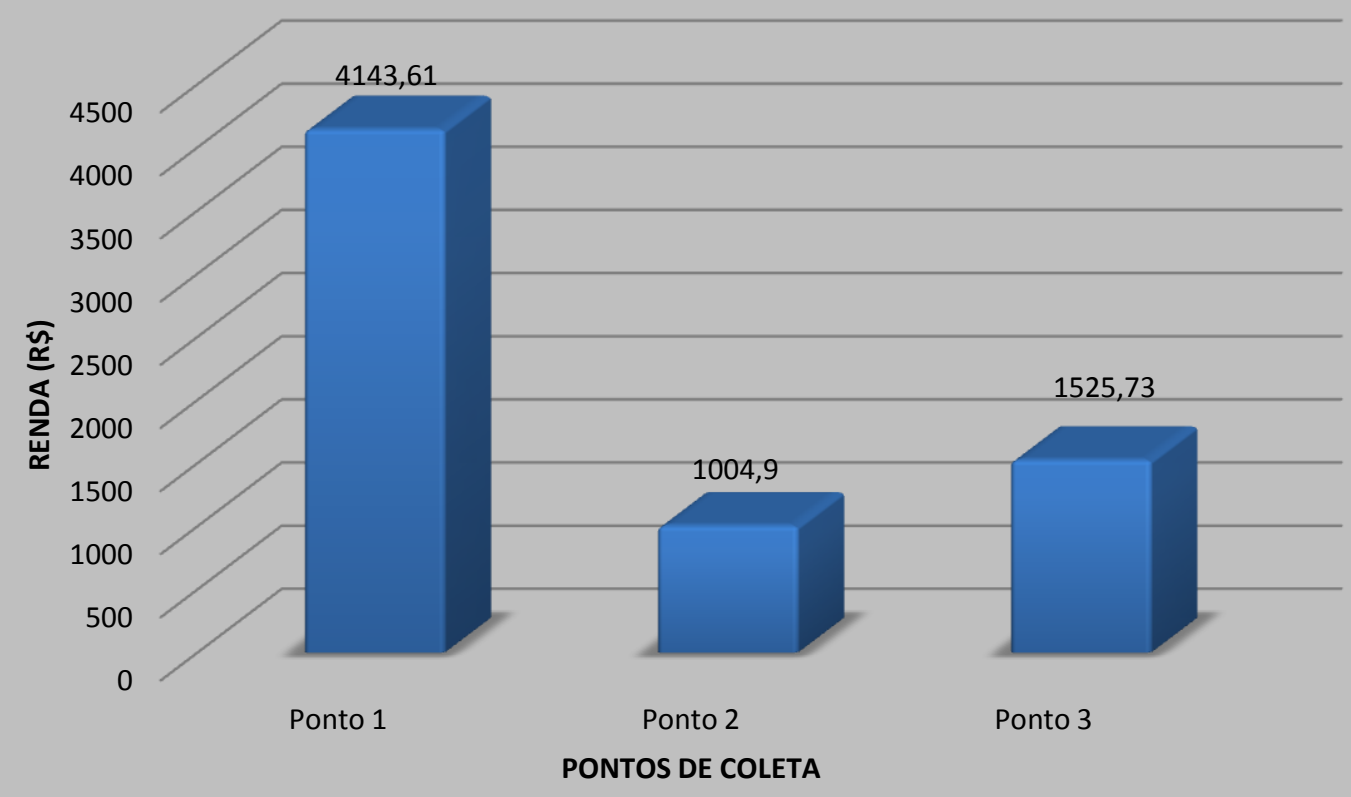

Figura 5: média da renda da população da área de estudo

Fonte: IBGE, 2010

\section{Coleta por domicílio}

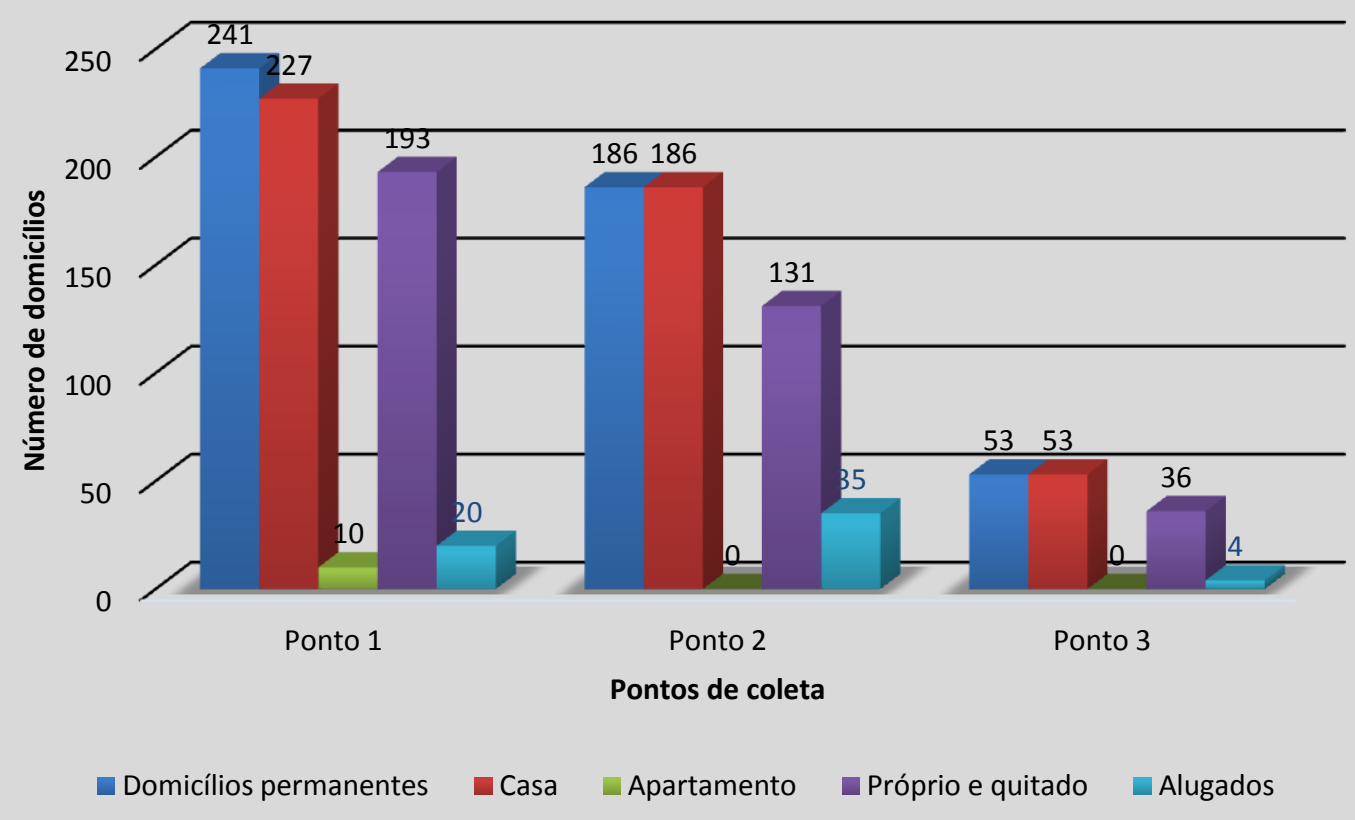

Figura 6: Tipos de domicilio da área de estudo

Fonte: IBGE, 2010 


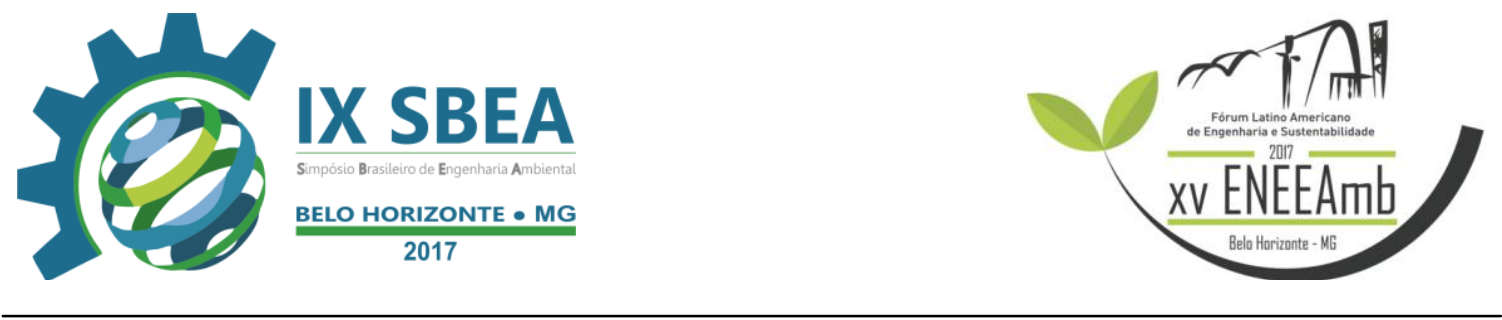

\subsection{Resultado da pesquisa realizada com os moradores}

A pesquisa foi realizada durante os meses de outubro e novembro de 2016, onde diversos problemas foram apontados pelos moradores. Os entrevistados foram pessoas de diferente faixa etária de idade, e apenas moradores da região. Na figura 7 mostra que pouco mais da metade dos entrevistados acham o córrego importante para a comunidade, apontando $59 \%$, enquanto $41 \%$ da população não acham o córrego importante.

\section{Você acha o córrego importante para a} comunidade?

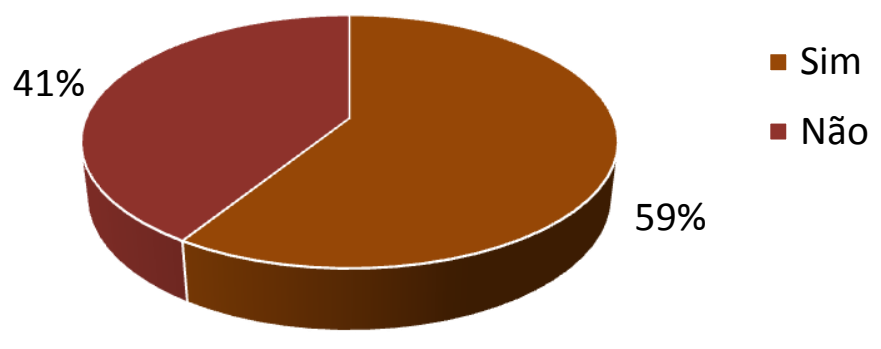

Figura 7: referente a questão 1 realizada, aplicada

à população do entorno da érea de estudo

A Figura 8 aponta que a maioria dos entrevistados já presenciaram descarte inadequado de resíduos no córrego ou no seu entorno, $72 \%$ dos entrevistados apontaram que frequentemente resíduos como: moveis, entulho, capina e poda e resíduos orgânicos são descartados no córrego, ou abandonados em suas margens, e 28\% apontaram que nunca precisaram nenhum tipo de descarte inadequado no córrego 


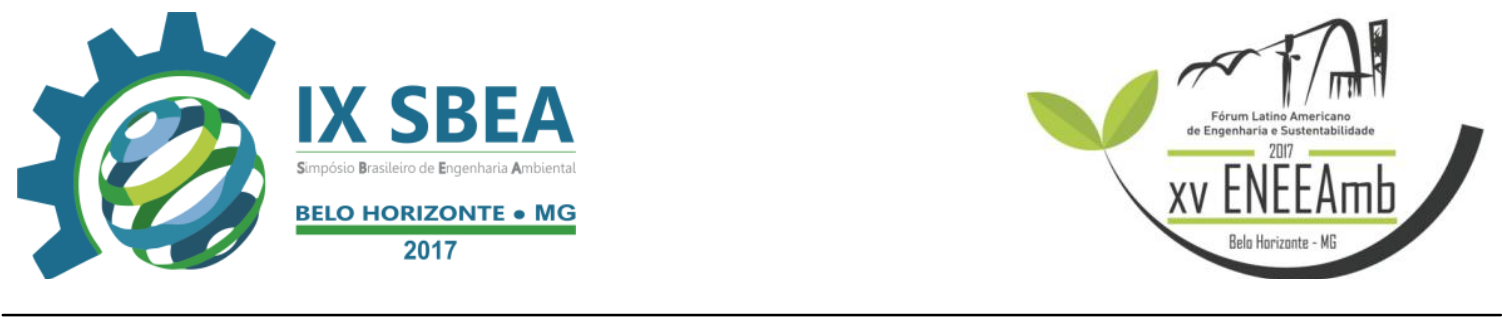

\section{Já presenciou algum descarte inadequado de resíduos do córrego?}

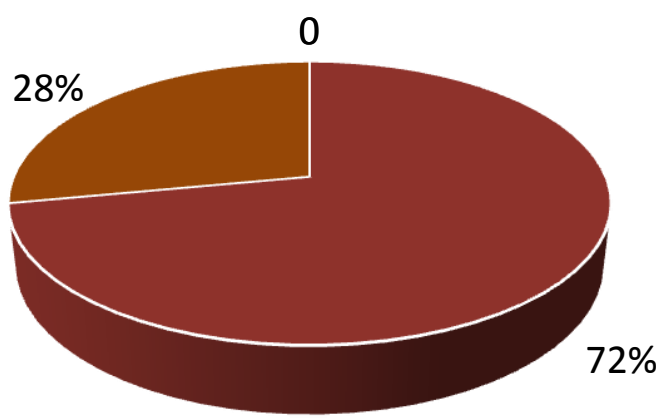

- Sim

- Não

Figura 8: referente a questão 2 realizada, aplicada

à população do entorno da érea de estudo

A figura 9 representa sobre a percepção dos moradores em relação as causas da poluição do córrego, $72,6 \%$ da população acham que essa poluição é advinda da população que moram no entorno, 21,9\% apontam que a poluição não é advinda da população que vive ali e sim de indústrias ou pessoas de bairros vizinhos, apenas 5,5\% da população não souberam responder essa pergunta.

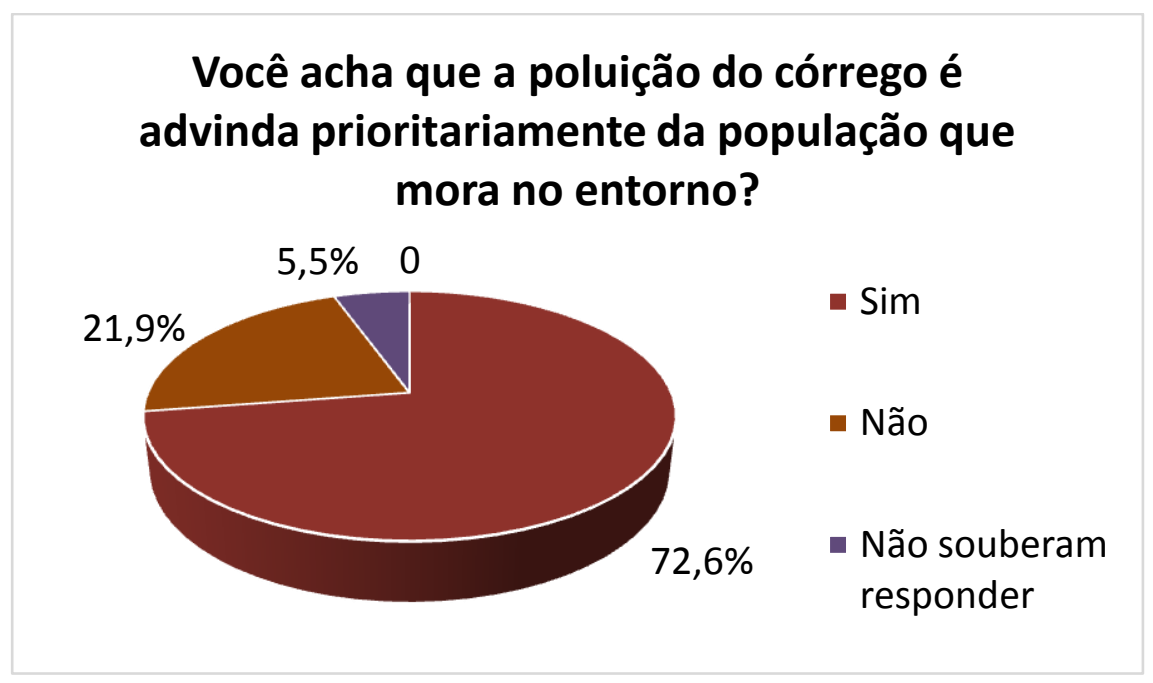

Figura 9: referente a questão 3 realizada, aplicada à população do entorno da érea de estudo 


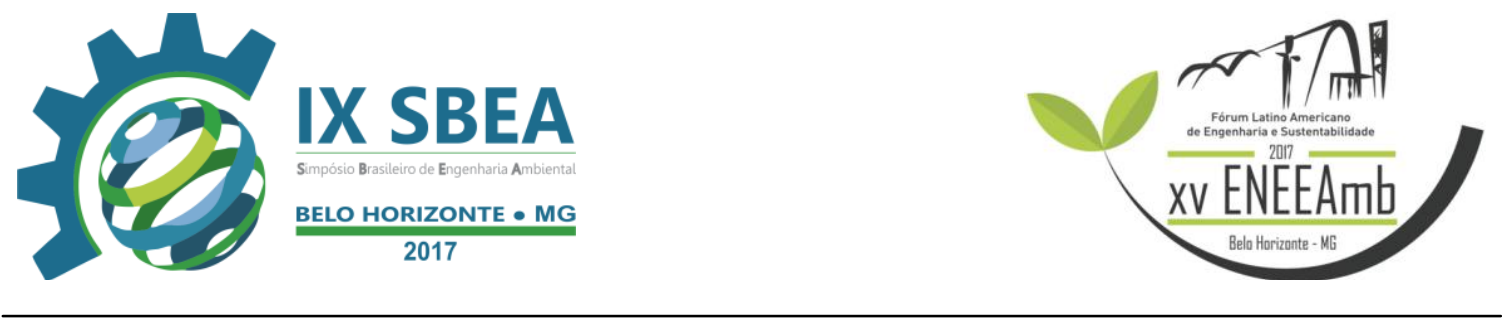

Sobre a coleta de lixo na região a figura 10 mostras que $66 \%$ da população afirma que existe a coleta frequente, e apenas 34\% afirmam não existir coleta frequente na região.

\section{Existe a coleta seletiva frequente na região?}

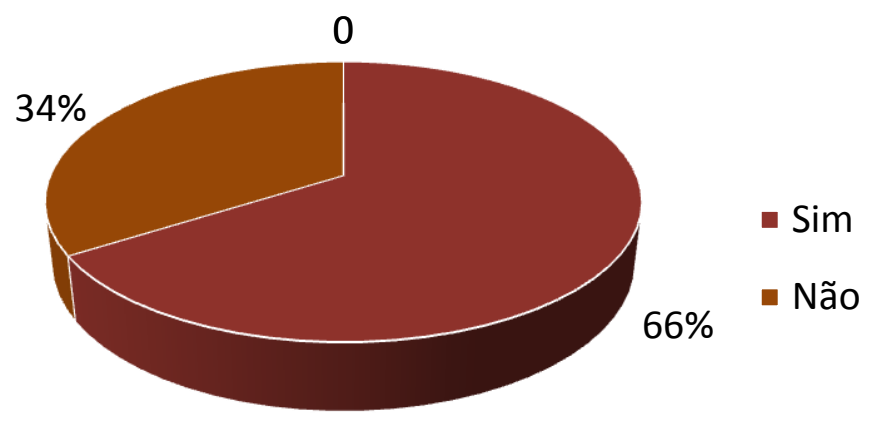

Figura 10: referente a questão 4 realizada, aplicada à população do entorno da érea de estudo

A figura 11 teve o objetivo de apontar os principais problemas que a população sofre com a presença do córrego, $68 \%$ da população afirmam que já foram prejudicados com alagamentos que são frequentes na região em épocas de fortes chuvas, $23 \%$ da população afirmam que a presença do rio traz doenças, e $9 \%$ dos entrevistados disseram que a presença do rio não prejudica em nada. 


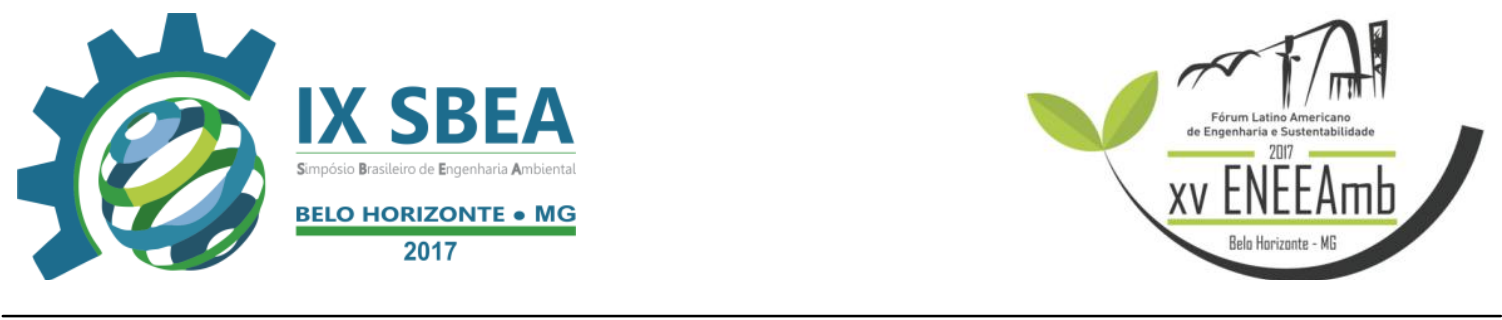

O que a presença do córrego e seus aspectos trás para a população

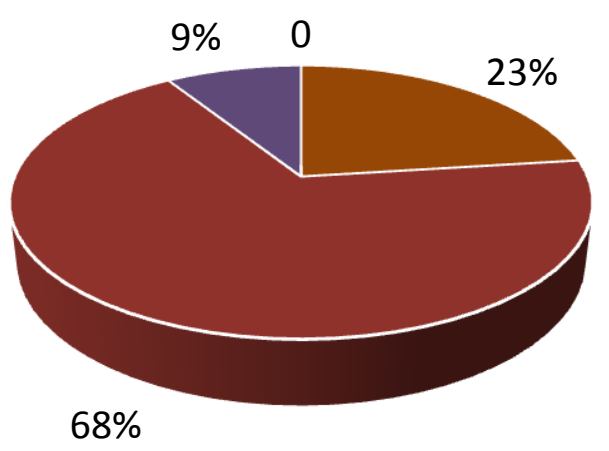

- Doenças

- Alagamentos

- Não prejudica

Figura 11: referente a questão 5 realizada, aplicada

à população do entorno da érea de estudo

A figura 12 apontam as principais soluções apontadas pelos entrevistados para a recuperação ou preservação do córrego, $46,5 \%$ que se os resíduos fossem descartados de maneira correta os problemas seriam solucionados, 34,2\% afirmam que é preciso a conscientização das pessoas por meio da educação ambiental, para que assim todos possam saber da devida importância do córrego e consequentemente preserva-lo, 19,3\% dos entrevistados afirmam que não podem fazer nada para essa preservação, e que apenas órgão públicos irão consegui solucionar esses problemas, esses mesmo 


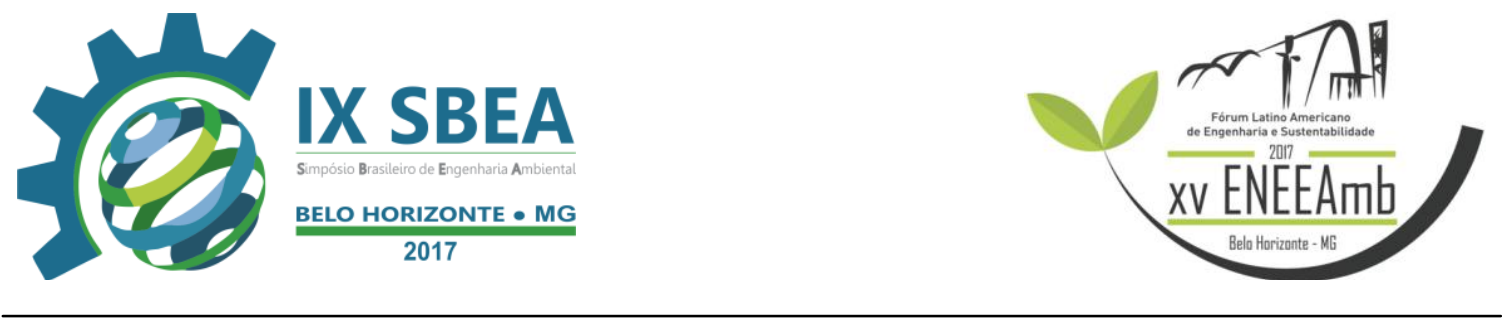

entrevistados apontam que uma das soluções para esse problema seria a canalização do córrego.

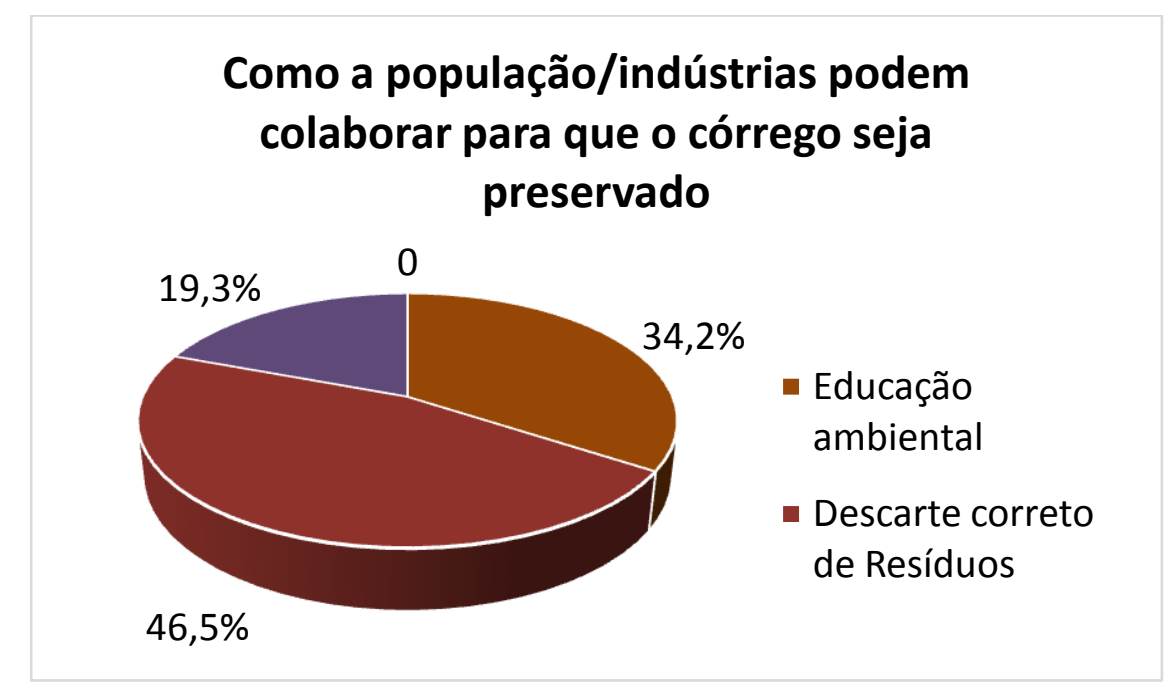

Figura 12: referente a questão 6 realizada, aplicada

à população do entorno da érea de estudo

\subsection{Concentração de pontos apontados pela população}

Através da pesquisa realizada com os moradores foi elaborado mapas com a concentração dos principais problemas apontados, como os alagamentos da região e coleta de lixo.

A figura 13 representa os pontos onde os moradores afirmam existir coleta frequente de resíduos. 

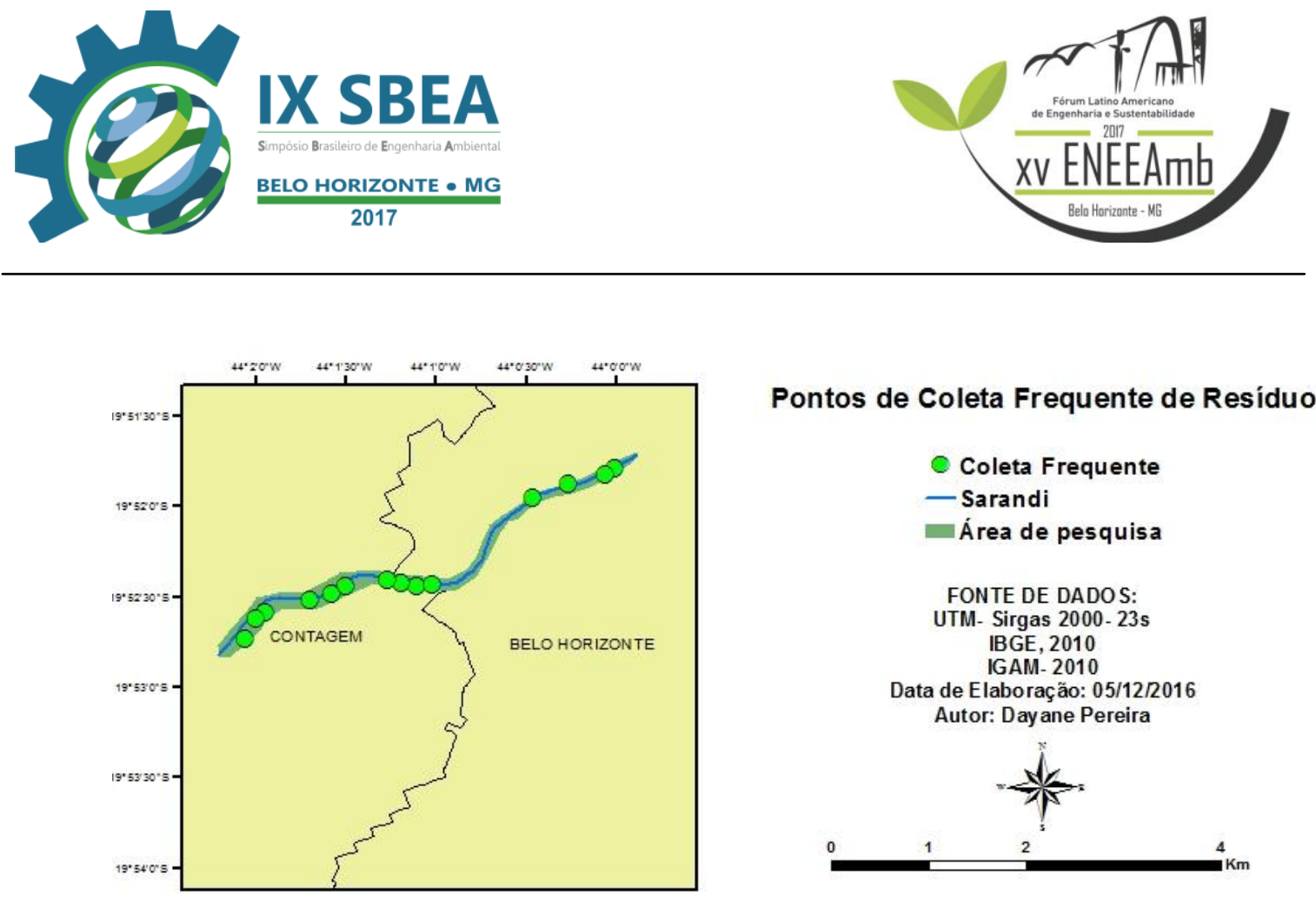

\section{Pontos de Coleta Frequente de Resíduos}

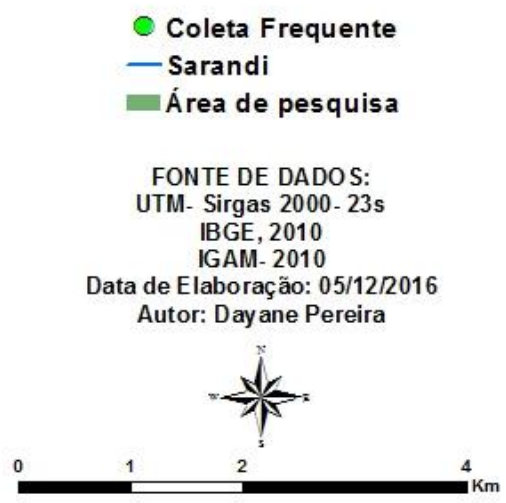

Figura 13 - Pontos de coleta frequente de resíduos

Fonte - Elaborado pelos autores, 2016

A figura 14 mostra os pontos onde os entrevistados apontam não existir coleta seletiva frequente de resíduos, eles levantaram, que a coleta comum existe porém, são descartados frequentemente na região outros tipos de resíduos como: entulho, moveis, capina e poda, entre outros, e para esse tipo de resíduos não existe coleta frequente.

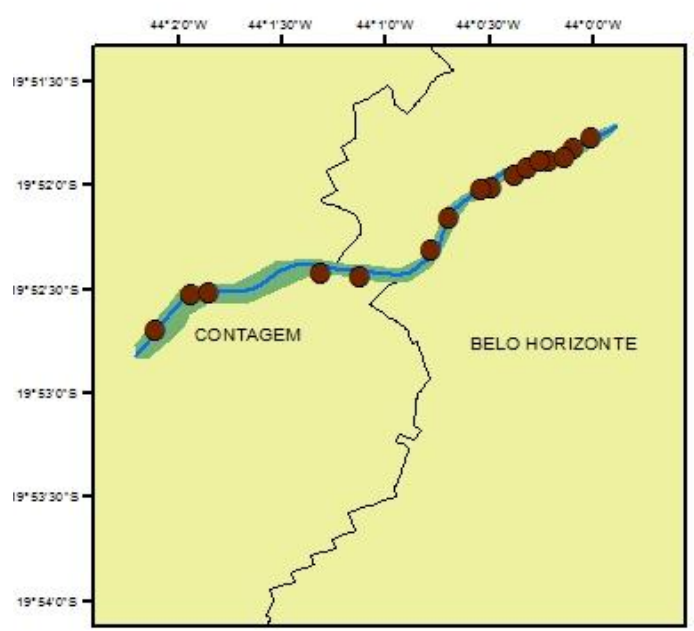

Pontos de Falta de Coleta Frequente de Resíduos

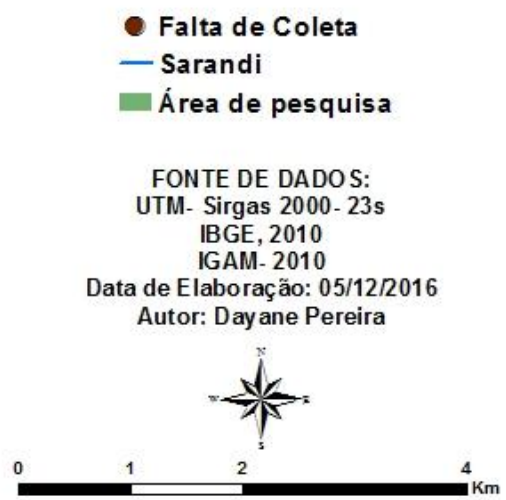

Figura 14 - Pontos de falta de coleta frequente de resíduos

Fonte - Elaborado pelos autores, 2016 
A figura 15 mostra os pontos onde os entrevistados afirmam existir alagamentos, segundo eles esses alagamentos são comuns em épocas de fortes precipitações.

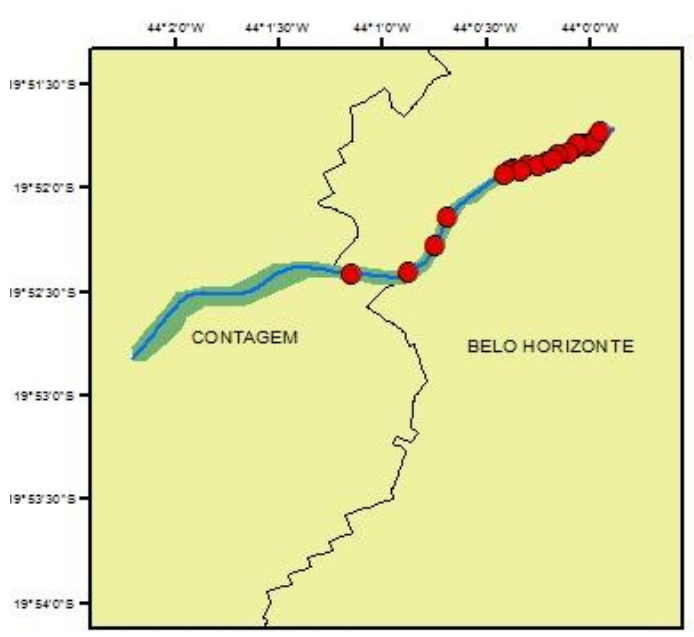

Pontos de alagamentos Frequentes

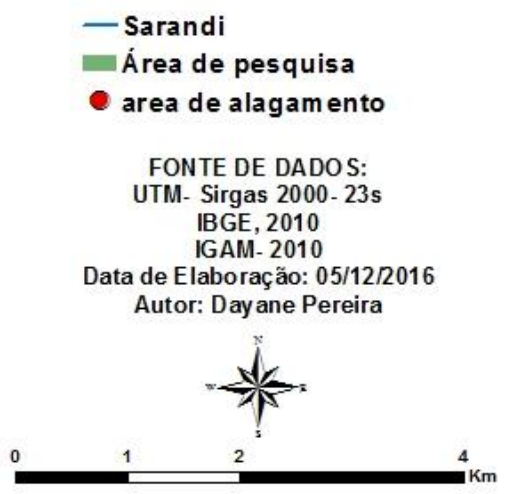

Figura 15 - Pontos de alagamentos frequentes

Fonte - Elaborado pelos autores, 2016

\subsection{Sobreposição dos dados}

Ao realizar o cruzamento dos dados pode-se observar alguns pontos importantes desse estudo. A áreas onde os moradores apontaram existir o maior número de enchentes, são também áreas onde eles apontam não existir coleta seletiva frequente, além de serem áreas com elevações mais baixas, tendo em média 808 metros como mostra a figura 16. 

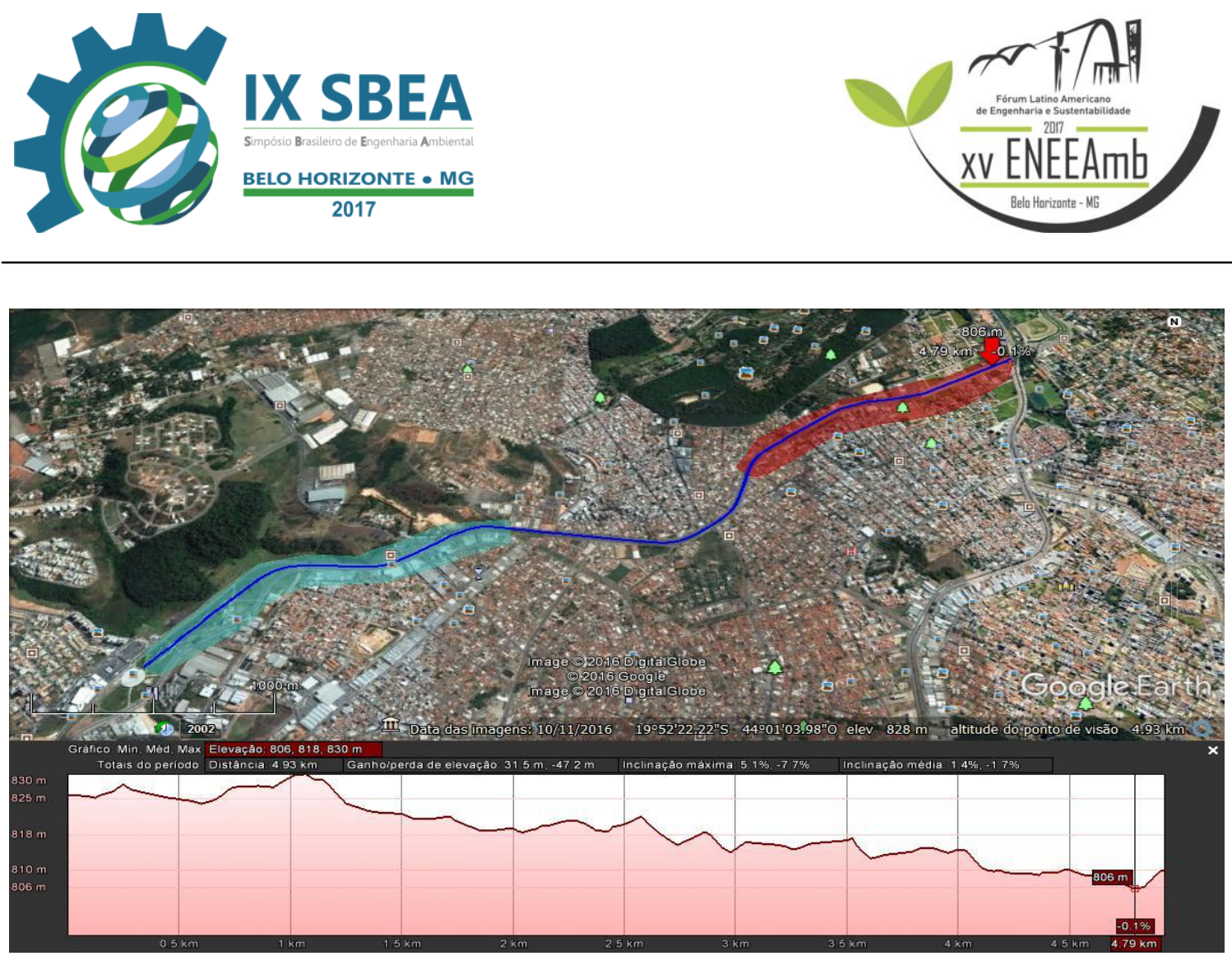

Figura 16 - Pontos de registro de alagamentos frequentes

Fonte - GOOGLE EARTH,2016

A área onde os entrevistados apontaram existir coleta seletiva frequente de resíduos são também áreas onde não existem registros de enchentes e além disso áreas com elevações mais altas chegando até 830 metros como mostra a figura 17.

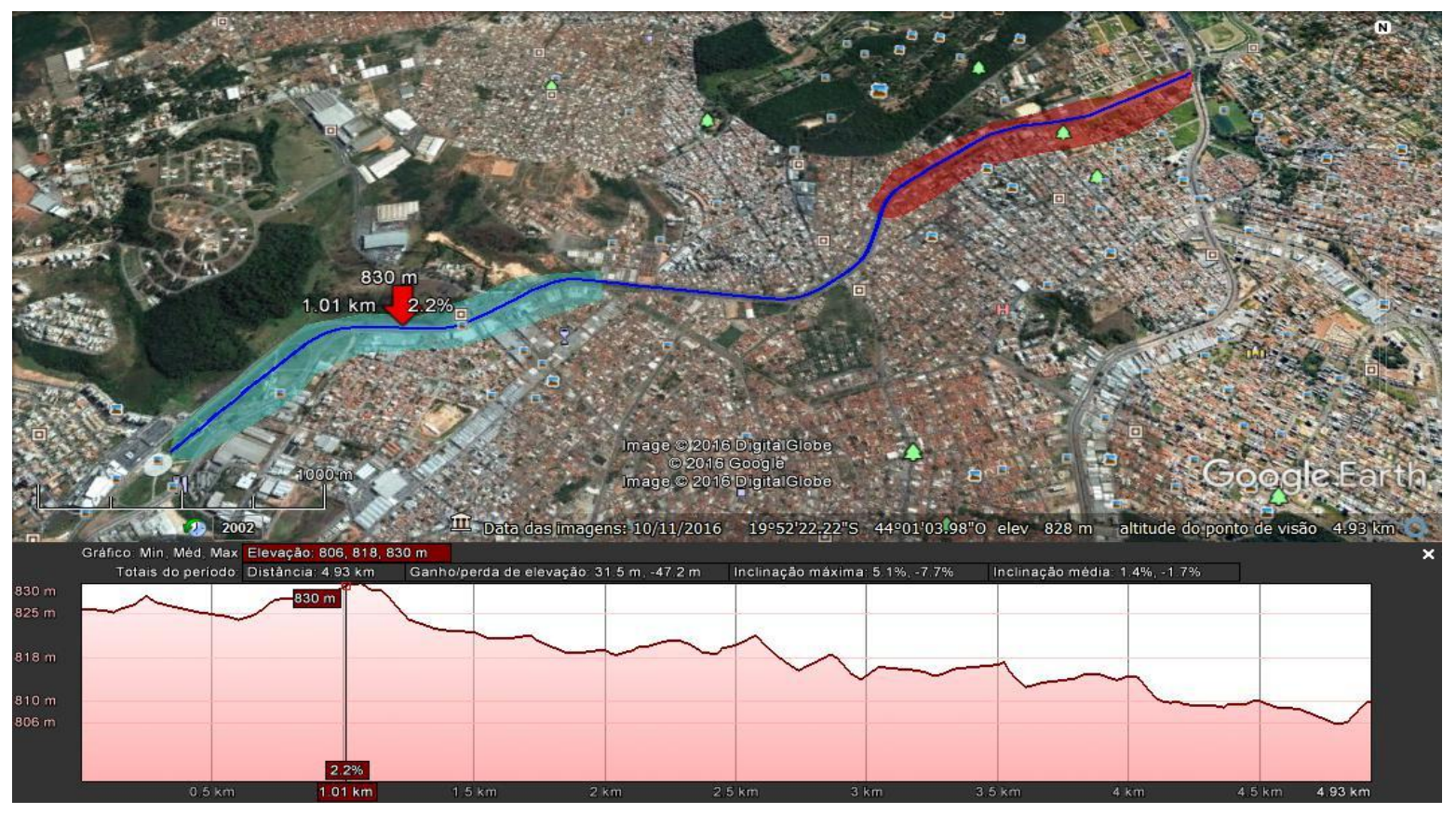

Figura 17 - Ponto onde não existe registro de alagamentos

Fonte - GOOGLE EARTH,2016 


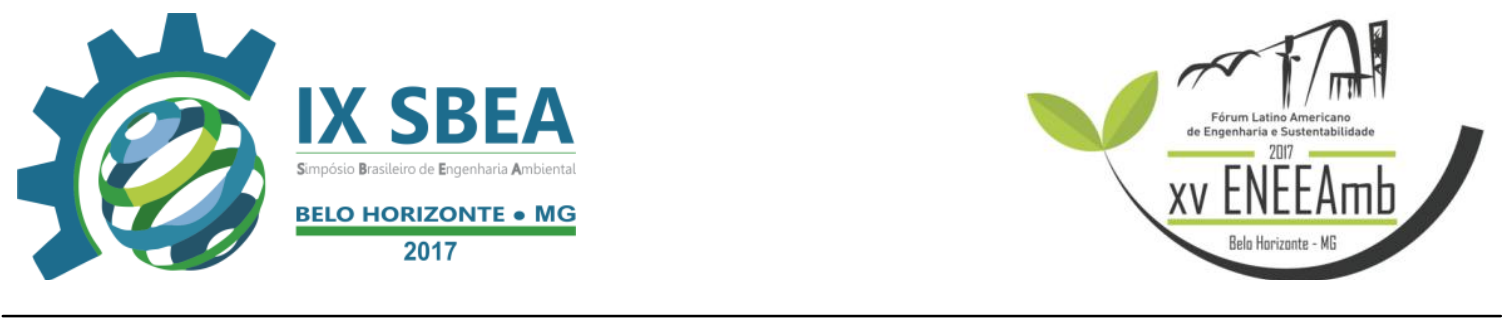

\section{CONCLUSÕES/RECOMENDAÇÕES}

A pesquisa em estudo pode mostrar que as áreas onde possui coleta de resíduos frequente e também são caracterizadas por um relevo mais elevado, existe poucas ou quase nenhuma ocorrências de enchentes, em contra partida as regiões de baixo relevo e que não possuem coleta de resíduos frequente, apresenta maior numero de ocorrência de enchentes. Observa-se também que os moradores das áreas do Córrego Sarandi entendem os problemas ocasionado pela poluição do mesmo, e apontam que há falta de iniciativas por parte de órgãos ou instituições de apoio.

O Córrego Sarandi desagua na lagoa da Pampulha, e faz parte de um dos projeto de Oscar Niemeyer, além de ser um dos mais importantes pontos turístico da cidade de Belo Horizonte. Ressalta-se que a área da bacia do Córrego, é uma região que necessita de um cuidado especial, visto que existe um número muito grande de pessoas que residem ao seu entorno. A poluição do curso d'água pode levar para população diversos problemas a saúde e também ao meio ambiente, entretanto é importante que medidas sejam tomadas para melhorar as condições socioambientais da região.

\section{REFERÊNCIAS BIBLIOGRÁFICAS}

COPASA - Companhia de Saneamento de Minas Gerais, 2016. Disponivel em: <http://www.copasa.com.br/wps/portal/internet>. Acesso em: 10 de out, 2016.

LEITE, A. E. B. Simulação do lançamento de esgotos domésticos em rios usando um modelo de qualidade d'água, SisBAHIA. 2004. Disponível em: <http://bvssp.icict.fiocruz.br/pdf/leiteaebm.pdf> . Acesso em 15 de Out, 2016

MORAIS. D. S. L, JORDÃO. B. Q. Degradação dos recursos hídricos e seus efeitos sobre a saúde humana, 2002. Diponivel em:< http://www.scielo.br/pdf/rsp/v36n3/10502>. Acesso em: 23 de Set, 2016.

RODRIGUES. R. Degradação e ocupação desordenada destroem nascentes da bacia da Pampulha, 2015. Disponível em: <http://www.manuelzao.ufmg.br/comunicacao/noticias/degrada\%C3\%A7\%C3\%A3o-eocupa\%C3\%A7\%C3\%A3o-desordenada-destroem-nascentes-da-bacia-da-pampulha>. Acesso em: 05 de Nov, 2016. 


\section{PBH-}

Prefeitura

Municipal

de

Belo

Horizonte, 2016.

Disponivel

em:

<http://portaldeservicos.pbh.gov.br/portalservicos/view/paginas/escolheHome.jsf;jsessi onid=E086D9EF1E9AB712E4BE5649B2279BE7.portal2>. Acesso em: 02 de Nov, 2016.

PHCRV- Projetos Hidroambientais do Comitê do Rio das Velhas. Ribeirão onça- SubBacia do Córrego Sarandi- ON147- Nascente 040-KM688, 2015. Disponível em: $<$ http://www.agbpeixevivo.org.br/nascentesurbanas/index.php/nascentes-doonca/nascentes-da-sub-bacia-corrego-sarandi/br-040-km-688>. Acesso em: 04 de Nov, 2016.

PROJETO BRASIL DAS ÁGUAS. A importância da água, 2012. Diposnivel em: $<$ http://brasildasaguas.com.br/educacional/a-importancia-da-agua/>. Acesso em: 05 de Nov, 2016.

BATISTA. A. P. Ações ambientais que visam a revitalização e preservação da lagoa
da $\quad$ Pampulha, <http://revistapensar.com.br/engenharia/pasta_upload/artigos/a109.pdf>. Acesso em: 28 de Nov, 2016.

PROJETO MANUESÃO. Lagoa da Pampulha, 2016. Disponível em: <http://www.manuelzao.ufmg.br/acontece/pampulha-viva3>. Acesso em: 16 de Nov, 2016.

SUDECAP, 2012. Bacia da Lagoa da Pampulha. Disponível em: <http://portalpbh.pbh.gov.br/pbh/ecp/comunidade.do?app=sudecap >. Acesso em: 19 nov, 2016. 